\title{
The Meaning of "Theory" in Biology
}

\author{
Massimo Pigliucci $\cdot$ Kim Sterelny $\cdot$ Werner Callebaut
}

Received: 1 June 2013/Accepted: 6 June 2013/Published online: 22 June 2013

(C) Konrad Lorenz Institute for Evolution and Cognition Research 2013

The articles in this issue reflect the results of the 25th Altenberg Workshop in Theoretical Biology on "The Meaning of "Theory' in Biology" held at the Konrad Lorenz Institute for Evolution and Cognition Research, Altenberg, Austria, 30 June-3 July, 2011. As the co-organizers of this event we warmly thank the KLI Board for sponsoring the workshop, and Eva Karner for taking wonderful care of the logistics.

Several articles deal with biological theory/theoretical biology as practice. In the opening article, Massimo Pigliucci compares the multifarious ways in which theory is "done" in biology - from formal analytic models to computer simulations, from graphic representations to verbal arguments-with theorizing in physics, and reviews recent attempts by ecologists to provide a conceptual framework for the whole of biology. James Griesemer contrasts

\footnotetext{
M. Pigliucci

Philosophy Program, The Graduate Center, City University of

New York, New York, NY, USA

e-mail: massimo@platofootnote.org

K. Sterelny

Philosophy and Tempo and Mode, Australian National

University, Canberra, ACT, Australia

e-mail: kim.sterelny@anu.edu.au

K. Sterelny

Victoria University of Wellington, Wellington, New Zealand

W. Callebaut $(\bowtie)$

Konrad Lorenz Institute for Evolution and Cognition Research,

Altenberg, Austria

e-mail: werner.callebaut@kli.ac.at

W. Callebaut

Department of Theoretical Biology, University of Vienna,

Vienna, Austria
}

"exact" and "inexact" sciences in terms of the formalization of their theories or lack thereof, and argues that formalization, involving any form/content distinction allowing forms to be studied independently of the empirical content of a subject-matter domain, is a broader category than mathematization. In Griesemer's view, "exactness" is not merely a state of a science but "a practice depending on the use of theories to control subject-matter domains and to align theoretical with empirical models." Inexact biological sciences tolerate a degree of "mismatch" between theoretical and empirical models and concepts. In her case study of the representational practices of geneticists in the 1910s, Marion Vorms challenges "theory-biased" approaches that focus on abstract structures independently from scientific agents' understanding, and urges us to study theorizing as a cognitive activity. Building on earlier work by Griesemer, Alan Love pictures theory structure in biology as consisting of idealized theory presentations that are always incomplete and shaped by their material rather than formal organization. Love also suggests replacing the problematic idea of a common core structure behind theory presentations with the notion of a "theory façade," viz., "descriptive patches representing different recipes for describing and reasoning about ... real world events" (Mark Wilson). Sabina Leonelli points out the relevance of classificatory activities for generating theories, and explores some of the characteristics of classificatory theories (such as bio-ontologies) used in experimental biology, and how they differ from other types of scientific theories. In the article that rounds off the issue, Werner Callebaut contrasts how philosophers and biologists have thought about theory in the last century, considers recent calls to upgrade the role of biological theory in response to the "data deluge" in molecular biology and other fields, and discusses aspects of a positive program for "naturalizing theorizing." 
The other contributions span a wide range of issues, reflecting the diverging but partially overlapping research interests within the philosophy of biology today. Roberta Millstein looks at the uses of population genetics to shed light on ecology and vice versa. Kim Sterelny discusses the evolution of human cooperation as an organizing example to revisit Mayr's "proximate/ultimate" distinction. Carol Cleland argues that if there are explanatorily and predictively powerful, biologically distinctive principles for life that can be gleaned from our "insular example" of life on Earth, they are likely to be found in the microbial world. David Depew highlights the rhetorical dimension in evolutionary theorizing from Darwin to the Modern Synthesis. Helen Longino offers a case study of the fate of scientific ideas about human behavior that are communicated to a broader audience. Jonathan Kaplan and Rasmus Winther argue for the "illegitimacy" of using biological theory to make claims about human "race."

A plea for establishing criteria for the determination of model utility prior to model construction (Louis Gross) that was also presented at the workshop, and an article on theory as a guide in molecular systems biology (Frank Bruggeman) that was prepared for, but not presented at the workshop, will appear in later issues of Biological Theory. 